\title{
Familial association of keratoconus and granular corneal dystrophy: The familial case series
}

\author{
(D) Cem Cankaya, ${ }^{1}$ (1) Abuzer Gunduz, ${ }^{1}$ (i) Tongabay Cumurcu, ${ }^{1}$ (i) Soner Demirel, ${ }^{1}$ \\ (D) Saliha Serap Savaci, ${ }^{2}$ (D) Mufide Cavdar ${ }^{1}$ \\ ${ }^{1}$ Department of Ophthalmology, Inonu University Faculty of Medicine, Malatya, Turkey \\ ${ }^{2}$ Department of Genetics, Inonu University Faculty of Medicine, Malatya, Turkey
}

\begin{abstract}
OBJECTIVE: The aim of the present study was to evaluate the coexistence of bilateral keratoconus and granular corneal dystrophy (GCD) in the members of a family.

METHODS: A total of 22 patients were examined in four generations of the family tree in this family screening study. Visual acuity test, biomicroscopic examination, and fundus examination were performed in all patients. The diagnosis of granular dystrophy was based on biomicroscopic examination findings. Corneal topography was performed on the patients diagnosed with granular dystrophy and other family members aged $>5$ years with normal examination findings. Corneal photographs were obtained from all patients with granular dystrophy except one case.

RESULTS: Keratoconus or subclinical keratoconus was detected in seven cases. In addition, GCD type 1 was found in six of the seven cases. All patients diagnosed with keratoconus and granular dystrophy were females. On the other hand, there was no ophthalmologic problem in the men of the family tree. Although an autosomal dominant inheritance was found, the onset of the disease only in women suggests that there may be a variant expression.

CONCLUSION: The present study showed an association of GCD and keratoconus in four generations of a family. More research is required to further explain this association.

Keywords: Corneal topography; granular corneal dystrophy; keratoconus; subclinical keratoconus.

Cite this article as: Cankaya C, Gunduz A, Cumurcu T, Demirel S, Savaci SS, Cavdar M. Familial association of keratoconus and granular corneal dystrophy: The familial case series. North Clin Istanb 2019;6(2):176-183.
\end{abstract}

$\mathrm{C}$ orneal dystrophies (CDs) are a group of hereditary disorders that generally become apparent in the first or second decades and are characterized by progressive accumulation of deposits in the cornea layers resulting in low corneal transparency [1].

Granular corneal dystrophy (GCD) has an autosomal dominant inheritance and causes focal white, snowflakelike opacities in the corneal stroma [2]. Type 1 is the most common type of granular dystrophy as characterized by multiple discrete crumb-like corneal opacities [1-3]. It usually begins in the first decade of life or in puberty with grayish-white opacities involving the superficial corneal stroma $[4,5]$. The opacities increase in number, expand, spread peripherally, and become deeper due to accumulation. However, a clear zone remains in the peripheral cornea. Finally, disk-shaped opacities are formed in the central cornea in the third or fourth decades [5].

Keratoconus is a disorder of corneal ectasia with nearly equal incidence in male and female populations and often occurs in the second decade of life. The diagnosis might be missed unless corneal topography is performed especially in early or mild cases [6]. The eti- 
ology and pathogenesis of keratoconus are not fully understood. Some genetic, environmental, biomechanical, and biochemical mechanisms have been proposed with various hypotheses [6]. There are many reports on keratoconus and coexisting ocular conditions, such as CDs, retinitis pigmentosa, and Leber's congenital amaurosis, but few reports discuss the association of keratoconus with GCD [7-13].

The association of keratoconus and GCD has been reported as case reports in the literature, but this association was noticed in four generations of a family in the present study. The study conducted by Mitsui et al. [14] is the first familial case series with respect to the association of keratoconus and GCD. To the best of our knowledge, this is the second familial case series in the literature.

\section{MATERIALS AND METHODS}

\section{Clinical Examination}

Best-corrected visual acuity (BCVA) test, biomicroscopic examination, and fundus examination were performed on 22 patients for family screening.

Corneal topography was performed on both eyes of adult patients with a diagnosis of granular dystrophy and all cases aged $>5$ years with normal ocular examination (except two non-compliant children aged 5 and 6 years). In addition, GCD cases were photographed in both eyes (except one case who did not want his photograph taken).

The Pentacam Scheimpflug system (Oculus, Wetzlar, Germany) was used for corneal topography. Topographic evaluation was evaluated based on the study by Ucakhan et al. [15] who used seven topographical evaluation models to determine keratoconus. Our study was based on Model 6 that contains the measurements of classic keratoconus changes in the cornea and parameters obtained from the posterior map of the cornea. These parameters are as follows: flat keratometry, steep keratometry, mean keratometry, central corneal thickness, minimum corneal thickness, MaxP4A* $\mathrm{A}^{*}$ axP4P* obtained with the posterior corneal map, MaxPE5*, MaxPD5*, PEDD*, $\mathrm{PEDD} / \mathrm{BFS}^{*}$, and $\mathrm{PER}^{*}{ }^{*}$ the abbreviations for these indices are explained in Appendix A).

All patients diagnosed with GCD with keratoconus and/or subclinical keratoconus were referred to the internal medicine, cardiology, and rheumatology departments regarding systemic diseases.

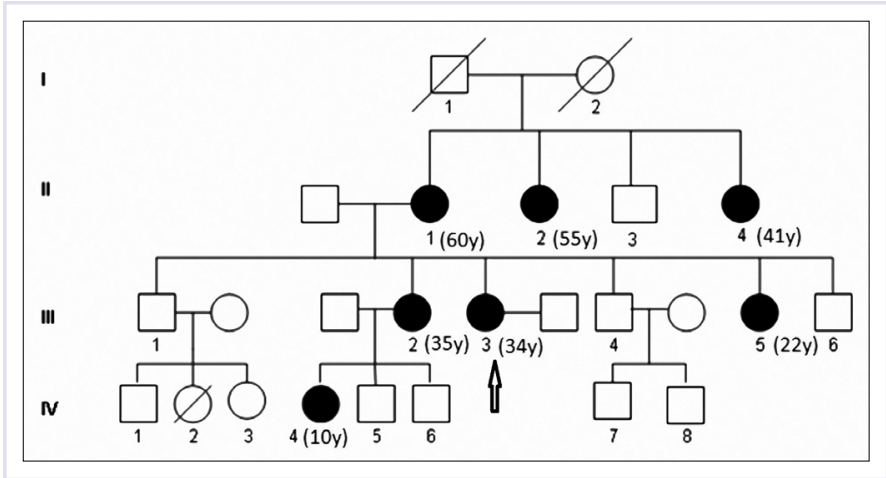

FIGURE 1. Demonstrating the four generations of affected members of the family pedigree ( $y$ : Years).

The study was approved by the local ethics committee of Inonu University. Consent forms were obtained from all patients who were enrolled in the study.

\section{Cases}

The cases were listed by their location in the pedigree (Fig. 1). This ranking was created by using the generation and sequence in the generation. There was no positive family story for patients with keratoconus and granular dystrophy. In addition, atopic signs, connective tissue diseases, or systemic diseases, such as diabetes, were not observed, and no patient had a history of refractive or non-refractive ocular surgery.

Case 1 (pedigree no. II-1): A 60-year-old mother of our proband case. She had no ocular complaint. Her BCVA was 20/20 unaided bilaterally. Bilateral slit lamp biomicroscopy revealed symmetrical, sharply demarcated, non-coalescent, grayish-white opacities only in the stroma layer (Fig. 2). The stroma between the opacities was transparent, and no epithelial defects or stromal haze was noted. Anterior segment and fundus examination results were within the normal limits in both eyes. She was diagnosed with bilateral subclinical keratoconus by topographic examination according to Ucakhan et al. [15] (Fig. 3A, B).

Case 2 (pedigree no. II-2)ः A 55-year-old aunt of our proband case. She had no ocular complaint. Her BCVA was 20/20 unaided bilaterally. On biomicroscopic inspection of the cornea, symmetrical, sharply demarcated, grayish-white, non-coalescent, star-shaped specular mild opacities were found only in the stroma layer. The stroma between the opacities was transparent, and no epithelial defects or stromal haze was noted. Anterior segment and 


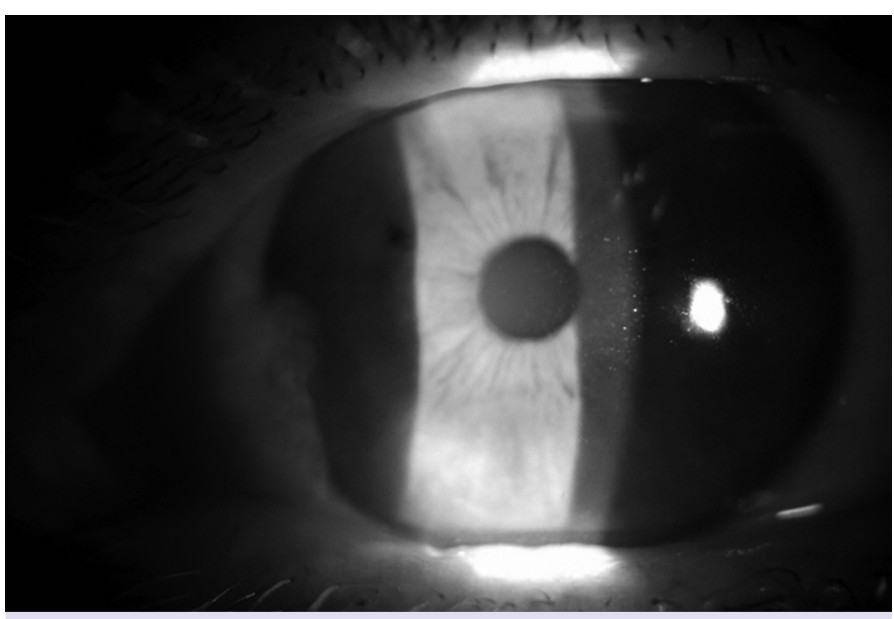

FIGURE2. Left eye corneal photograph of Case 1. Opacities of granular corneal dystrophy were seen in the corneal stroma.

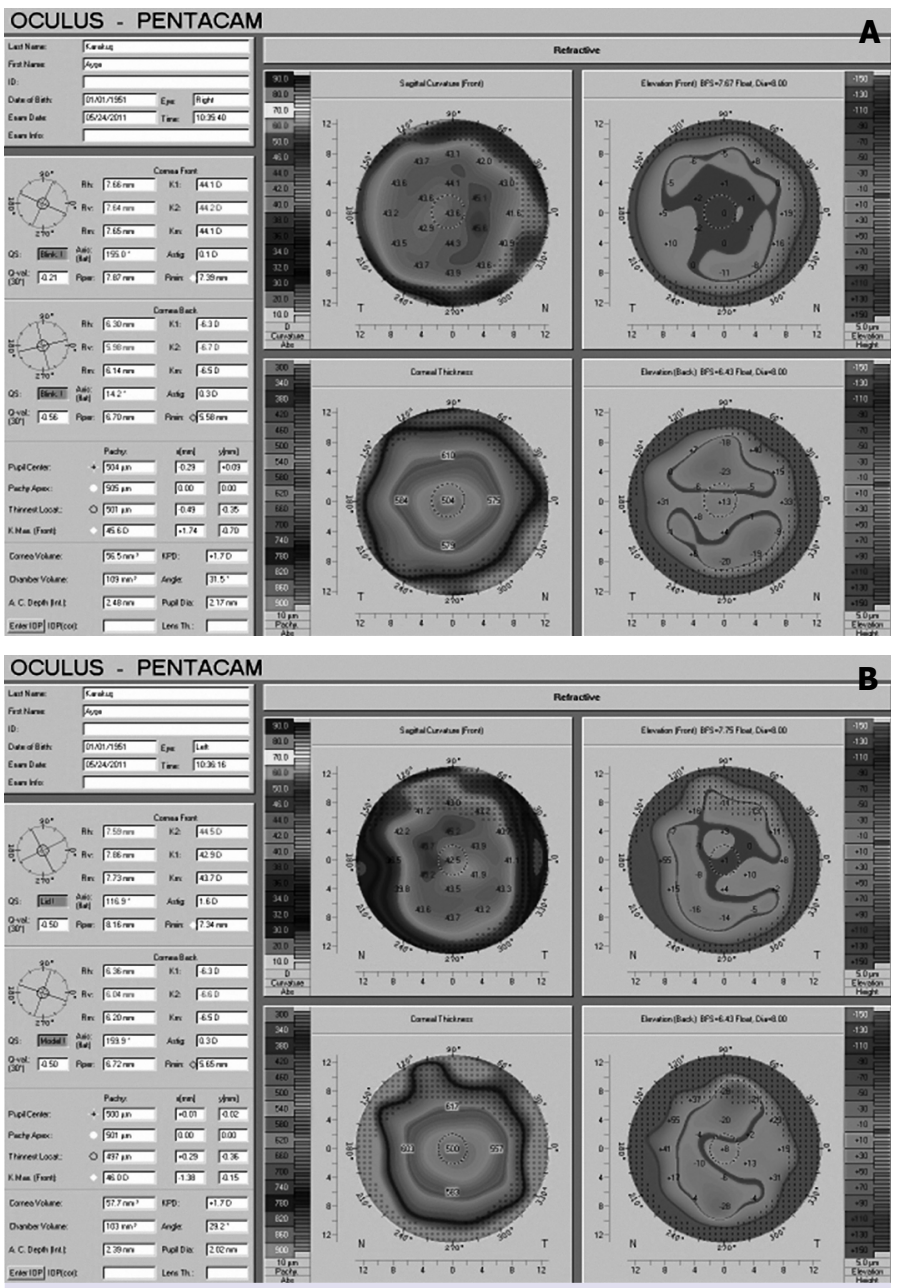

FIGURE 3. (A) Subclinical keratoconus findings in the right eye topograph of Case 1 (mother of the proband). (B) Subclinical keratoconus findings in the left eye topograph of Case 1 (mother of the proband).

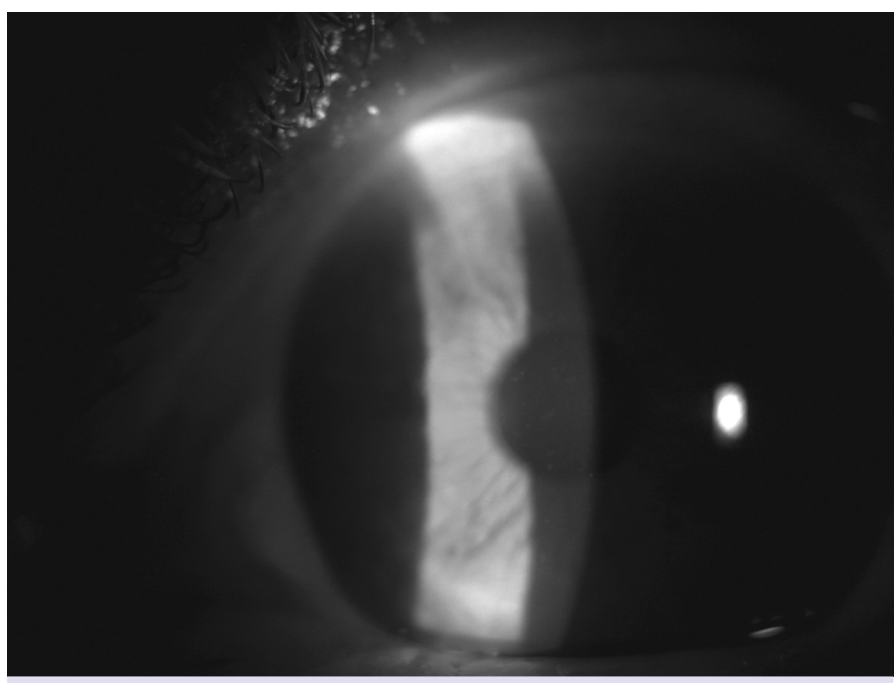

FIGURE 4. Right eye photograph of the proband (Case 4). Sharply demarcated, grayish-white, non-coalescent, starshaped opacities localized only to the stroma.

fundus examination results were within the normal limits in both eyes. She was diagnosed with bilateral subclinical keratoconus by topographic examination.

Case 3 (pedigree no. II-4): A 41-year-old other aunt of our proband case. She complained of blurred vision in both eyes. BCVA was $20 / 20(-1.5-2.25 \times 25)$ in the right and $20 / 20(-1.00-1.5 \times 165)$ in the left eye. A Fleischer's ring was seen in both eyes without any anterior or posterior segment pathology on biomicroscopic examination. She was diagnosed with bilateral clinical keratoconus by topographic examination.

Case 4 (pedigree no. III-2): This was the first diagnosed case, a 35-year-old female. She presented at our outpatient clinic with complaints of bilateral blurred vision. BCVA with contact lenses was 20/30 in the right eye (spherical value of contact lens: s-9.0) and 20/30 in the left eye (spherical value of contact lens: -9.5 ). Corneal ectasia with the presence of Vogt's striae and a Fleischer's ring and sharply demarcated, grayish-white, non-coalescent, star-shaped opacities localized only to the stroma were found bilaterally on biomicroscopic examination (Fig. 4). Anterior segment and fundus examination results were within the normal limits in both eyes. She was diagnosed with bilateral clinical keratoconus by topographic examination (Fig. 5A, B).

Case 5 (pedigree no. III-3): A 34-year-old sister of our proband case. She had no ocular complaint. Her BCVA was 20/20 unaided bilaterally. Biomicroscopic inspection revealed bilateral and symmetrical, sharply 


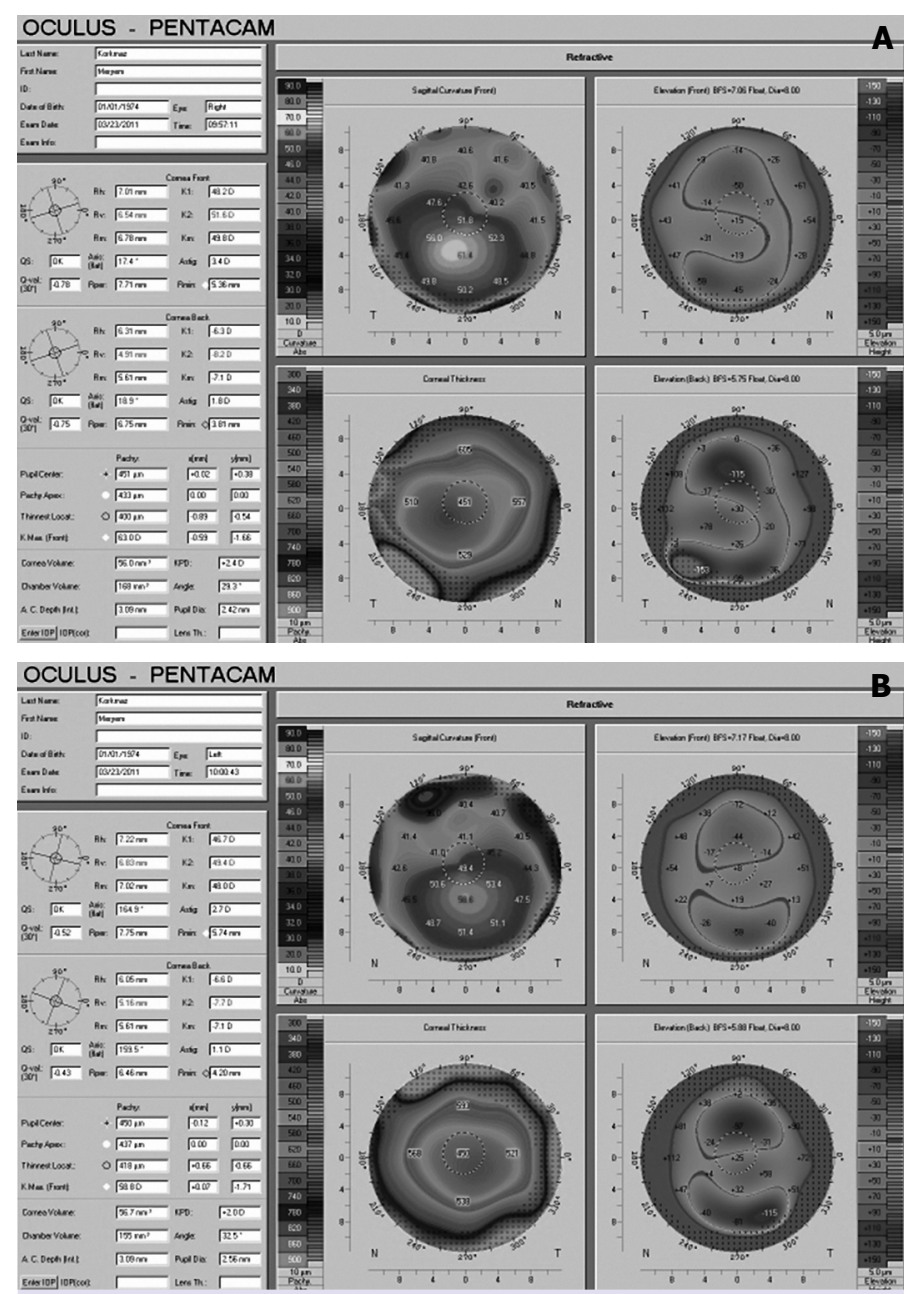

FIGURE 5. (A) Keratoconus findings in the right eye topograph of the proband (Case 4). (B) Keratoconus findings in the left eye topograph of the proband (Case 4).

demarcated, grayish-white, non-coalescent, star-shaped specular mild corneal opacities only in the stroma layer. The stroma between the opacities was transparent, and no epithelial defects or stromal haze was noted. The anterior segment and fundus examination results were within the normal limits in both eyes. She was diagnosed with bilateral subclinical keratoconus by topographic examination.

Case 6 (pedigree no. III-5): A 22-year-old other sister of our proband case. She had no ocular complaint. Her BCVA was 20/20 unaided bilaterally. Similar to other cases, bilateral and symmetrical, sharply demarcated, grayish-white, non-coalescent, star-shaped specular mild opacities were seen only in the stroma layer on biomicroscopic examination. The stroma between the opacities was transparent, and no epithelial defects

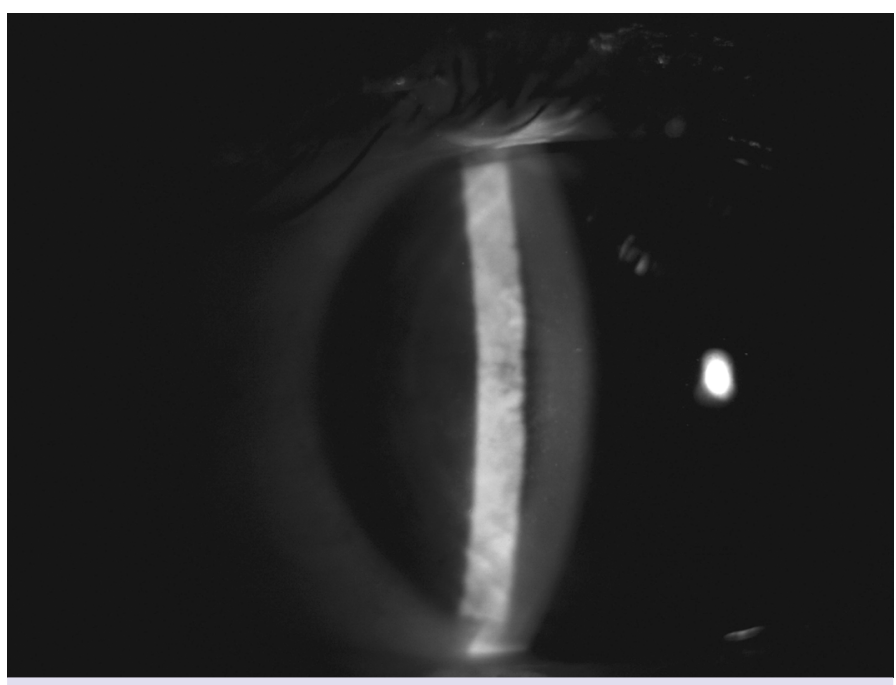

FIGURE 6. Left eye corneal photograph of Case 7. Opacities of granular corneal dystrophy were seen in the corneal stroma.

or stromal haze was noted. Anterior segment and fundus examination results were within the normal limits in both eyes. She was diagnosed with bilateral subclinical keratoconus by topographic examination.

Case 7 (pedigree no. IV-4)ः A 10-year-old daughter of our proband case. She had no ocular complaint. Her BCVA was 20/20 unaided bilaterally. Similar to other cases, bilateral and symmetrical, sharply demarcated, grayish-white, non-coalescent, star-shaped specular mild opacities were seen only in the stroma layer on biomicroscopic examination (Fig. 6). The stroma between the opacities was transparent, and no epithelial defects or stromal haze was noted. Anterior segment and fundus examination results were within the normal limits in both eyes. She was diagnosed with bilateral subclinical keratoconus by topographic examination (Fig. 7A, B).

\section{RESULTS}

A total of 22 cases were examined in this family screening study, and clinical and/or subclinical keratoconus was identified in seven cases (Table 1). Of the seven cases, six were diagnosed with GCD type 1 . All cases diagnosed with keratoconus or GCD were females, and the males were healthy. Judging by the pedigree view (Figure 1 ), the disease appears to have an autosomal dominant transition. However, the onset of disease only in women suggests that there might be a variant expression.

Internal medicine, cardiology, and rheumatologic examination results were all reported as normal. 


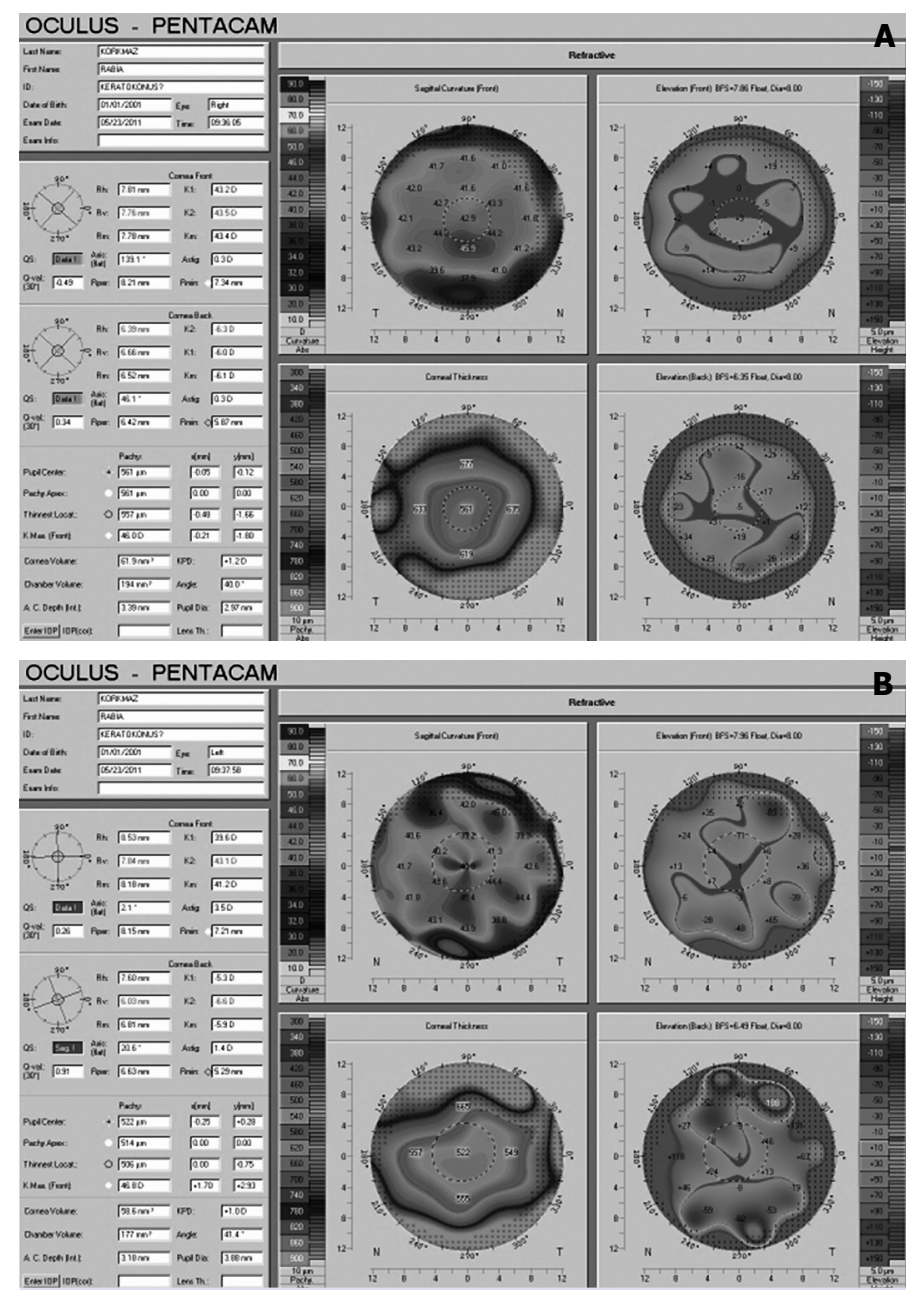

FIGURE7. (A) Subclinical keratoconus findings in the right eye topograph of Case 7 (daughter of the proband). (B) Subclinical keratoconus findings in the left eye of Case 7 (daughter of the proband).

\section{Genetic Research Result}

Corneal examination revealed keratoconus in seven out of 15 cases. All of the affected cases were females. In six out of these seven cases, keratoconus and GCD association was detected. In seven cases diagnosed with keratoconus, the previously defined G160D mutation was detected.

\section{DISCUSSION}

The possible causes and mechanisms of keratoconus are poorly understood despite studies to elucidate the etiology and pathogenesis of the disorder in recent years. Associations with some genetic-biochemical findings and some disorders, such as ocular or systemic, have been

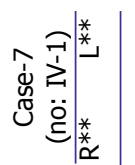

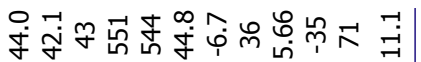

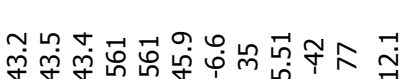

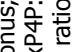
总 $\sum^{\frac{\pi}{2}} \frac{1}{0}$

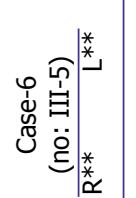

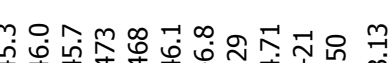
$\ddot{*} \ddot{*} \div$ बें

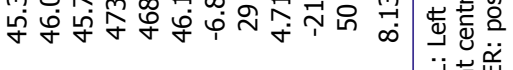

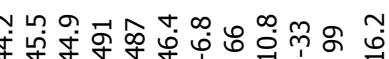
बें

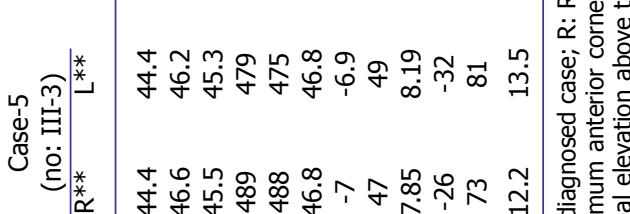

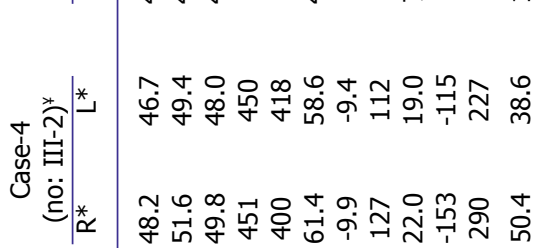
类就要

$\stackrel{0}{ \pm}$

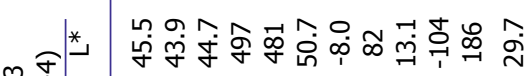

离

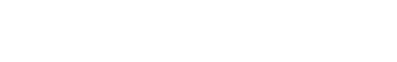

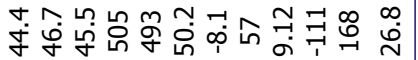

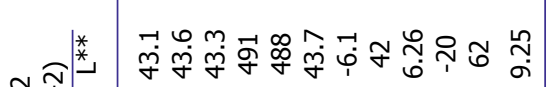

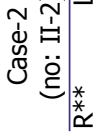

4

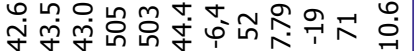

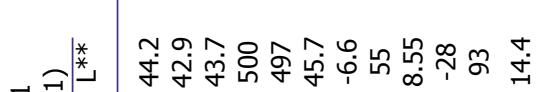

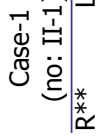

ร.

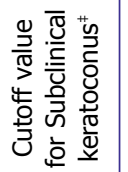

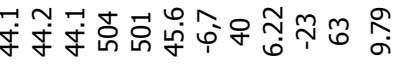

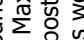

o

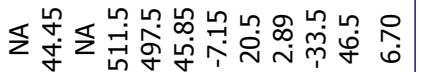

든

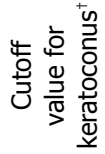

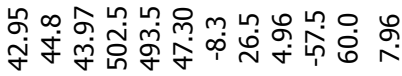

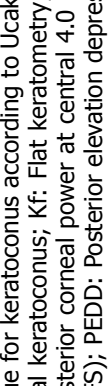

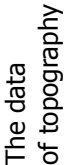

\section{高気产}

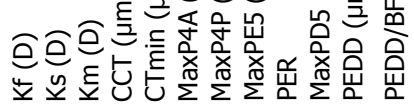


demonstrated. There are few reported sporadic cases on keratoconus associated with granular dystrophy. In the present study, familial GCD cases associated with keratoconus were reported. To our knowledge, this is the first study on familial GCD cases associated with keratoconus shown in the literature.

Keratoconus is generally known as an isolated condition, but has also been described in association with many syndromes or disorders $[8,16]$, such as Down's syndrome $[17,18]$, Leber's congenital amaurosis [19], Ehler-Danlos syndrome [20], osteogenesis imperfecta [21], mitral valve prolapse [22], atopy [23, 24], and vernal keratoconjunctivitis [25]. Therefore, systemic evaluations were performed for all patients in our familial screening study, and none of the individuals was found to have a disorder that could be associated with keratoconus.

We believe that the incidence of keratoconus and granular dystrophy association may be higher than mentioned in past reports of the literature as the early stages of keratoconus may not be detected on routine eye examination. In addition, the keratoconus incidence has changed significantly after the introduction of corneal topography. The rate of keratoconus in close relatives of patients with keratoconus was reported to be $6 \%-8 \%$ before topographic cornea examination was available and increased to $50 \%$ in recent studies [26-28].

The GCD and keratoconus association (clinical and subclinical keratoconus) was demonstrated in each female case in the present study. Our topography device and the keratoconus diagnosis model [15] that was developed for this device to demonstrate early keratoconus may have influenced this presentation as there was no keratoconus diagnosis model in previous studies.

Keratoconus has been suggested to have autosomal dominant inheritance with variable expression, and GCD has autosomal dominant inheritance [27-30]. The association of GCD and keratoconus had an autosomal dominant inheritance, but it is interesting that all affected individuals were females in our study, and this has not been previously reported in the literature. We believe that this might be a variant expression of autosomal dominant inheritance and have now consulted the Genetics Department for genetic research.

Many theories propose that the development of keratoconus is a result of the structural component loss of the cornea. Factors involved in the develop- ment of keratoconus have been identified as increased corneal proteolytic enzyme and interleukin-1 receptor levels, decreased proteinase inhibitor levels, and collagen type XIII, XV, and XVII changes [30-35]. Anterior stromal keratocyte loss, increase of interleukin-1 and interleukin-6, and decrease of interleukin-10 have been identified, and thinning of the corneal stromal lamellar structure and oxidative damage are found to be effective in the formation of keratoconus in other studies [36-46].

Various cells, collagen types, enzymes, and other mediators have shown to be influential in the development of keratoconus. However, more detailed investigation of these cells and mediators is needed to reveal the etiology of GCD and understand why keratoconus develops in patients with GCD. We could not perform such a study for ethical reasons as the patients had a good level of vision. Histopathological examination will be possible in the future if the patients require keratoplasty. Therefore, useful information for understanding the association of these two clinical entities could be obtained.

The coexistence of keratoconus and GCD was described for the first time by Mitsui [14] who reported the association of keratoconus and corneal granular dystrophy in a mother and her two sons. However, one of the sons had only keratoconus. We observed the association of keratoconus and corneal granular dystrophy only in the females of the four generations.

We believe that this association has an autosomal dominant inheritance with a different expression. Further studies are needed to clarify the etiology of this association.

Our study has limitations. One important limitation of the study is the number of subjects. We believe that more valuable results could be obtained if all of the family members could be included in the study. Another important limitation of our study is inadequate genetic analyses. Although we have found an association between corneal granular dystrophy and keratoconus disease, and we think that this association is caused by a variant expression, the clear localization and definition of this variant gene could not be identified.

In conclusion, the present study showed a familial association of GCD and keratoconus in four generations. The present study also showed autosomal dominant inheritance with a variant expression. 


\section{Appendix}

$\mathrm{BFS}=$ best-fit sphere

MaxP4A =maximum power measurement at the central $4.0 \mathrm{~mm}$ of the anterior corneal surface. Obtained by moving the cursor to the steepest point on the anterior sagittal curvature map.

$\mathrm{Max} 4 \mathrm{P}=$ maximum power measurement at the central $4.0 \mathrm{~mm}$ of the posterior corneal surface. Obtained by moving the cursor to the steepest point on the posterior sagittal curvature map.

MaxPD5=maximum depression value below the BFS at the central $5.0 \mathrm{~mm}$ of the posterior elevation map. Obtained by moving the cursor to the lowest point on the posterior elevation map.

MaxPE5=maximum elevation value above the BFS at the central $5.0 \mathrm{~mm}$ of the posterior elevation map. Obtained by moving the cursor to the highest point on the posterior elevation map.

$\mathrm{PEDD}=$ posterior elevation depression difference. $\mathrm{Ob}$ tained from the posterior elevation data. The highest minus the lowest value above and below the BFS (PEDD $=$ MaxPE5-MaxPD5).

$\mathrm{PEDD} / \mathrm{BFS}=$ obtained from the posterior elevation data. The posterior elevation depression difference divided by the BFS.

$\mathrm{PER}=$ posterior elevation ratio. Obtained from the posterior elevation data. The maximum elevation value above the BFS at the central $5.0 \mathrm{~mm}$ of the posterior elevation map divided by the BFS (PER=MaxPE5/BFS).

Conflict of Interest: The authors declare no conflict of interest.

Financial Disclosure: The authors have no proprietary or financial interest in any products used in this study.

Authorship Contributions: Concept - AG, TC; Design - CC, SD; Supervision - AG, TC; Materials - MC, CC; Data collection and/or processing - CC, MC, SD, SSS; Analysis and/or interpretation - CC, SD, AG, SSS; Writing - SD, CC; Critical review - TC, AG.

\section{REFERENCES}

1. Chang SW, Tuli S, Azar DT. Corneal dystrophies. In: Traboulsi EI, editor. Genetic diseases of the eye. New York: Oxford University Press; 1998. p. 217-66.

2. Wollensak G, Green WR, Temprano J. Keratoconus associated with corneal granular dystrophy in a patient of Italian origin. Cornea 2002;21:121-2. [CrossRef]

3. Collin HB, Hendicott PL. Granular dystrophy of the cornea. Clin Exp Optom 1999;82:203-6. [CrossRef]

4. Møller HU. Granular corneal dystrophy Groenouw type I. Clinical and genetic aspects. Acta Ophthalmol Suppl 1991:1-40.

5. Haddad R, Font RL, Fine BS. Unusual superficial variant of granular dystrophy of the cornea. Am J Ophthalmol 1977;83:213-8. [CrossRef]

6. Romero-Jiménez M, Santodomingo-Rubido J, Wolffsohn JS. Keratoconus: a review. Cont Lens Anterior Eye 2010;33:157-66. [CrossRef]

7. Nowak DM, Gajecka M. The genetics of keratoconus. Middle East Afr J Ophthalmol 2011;18:2-6. [CrossRef]

8. Rabinowitz YS. Keratoconus. Surv Ophthalmol 1998;42:297-319.

9. Sassani JW, Smith SG, Rabinowitz YS. Keratoconus and bilateral lattice-granular corneal dystrophies. Cornea 1992;11:343-50. [CrossRef]

10. Vajpayee RB, Snibson GR, Taylor HR. Association of keratoconus with granular corneal dystrophy. Aust N Z J Ophthalmol 1996;24:369-71.

11. Cremona FA, Ghosheh FR, Rapuano CJ, Eagle RC Jr, Hammersmith $\mathrm{KM}$, Laibson PR, et al. Keratoconus associated with other corneal dystrophies. Cornea 2009;28:127-35. [CrossRef]

12. Igarashi S, Makita Y, Hikichi T, Mori F, Hanada K, Yoshida A. Association of keratoconus and Avellino corneal dystrophy. Br J Ophthalmol 2003;87:367-8. [CrossRef]

13. Rathi VM, Vemuganti GK, Sangwan VS, Kannabiran C. Late occurrence of granular dystrophy in bilateral keratoconus: penetrating keratoplasty and long-term follow-up. Indian J Ophthalmol 2011;59:398400. [CrossRef]

14. Mitsui M, Sakimoto T, Sawa M, Katami M. Familial case of keratoconus with corneal granular dystrophy. Jpn J Ophthalmol 1998;42:385-8.

15. Uçakhan ÖÖ, Cetinkor V, Özkan M, Kanpolat A. Evaluation of Scheimpflug imaging parameters in subclinical keratoconus, keratoconus, and normal eyes. J Cataract Refract Surg 2011;37:1116-24.

16. Li X, Rabinowitz YS, Rasheed K, Yang H. Longitudinal study of the normal eyes in unilateral keratoconus patients. Ophthalmology 2004;111:440-6. [CrossRef]

17. Krachmer JH, Feder RS, Belin MW. Keratoconus and related noninflammatory corneal thinning disorders. Surv Ophthalmol 1984;28:293-322. [CrossRef]

18. Shapiro MB, France TD. The ocular features of Down's syndrome. Am J Ophthalmol 1985;99:659-63. [CrossRef]

19. Elder MJ. Leber congenital amaurosis and its association with keratoconus and keratoglobus. J Pediatr Ophthalmol Strabismus 1994;31:3840 .

20. Kuming BS, Joffe L. Ehlers-Danlos syndrome associated with keratoconus. A case report. S Afr Med J 1977;52:403-5.

21. Beckh U, Schönherr U, Naumann GO. Autosomal dominant keratoconus as the chief ocular symptom in Lobstein osteogenesis imperfecta tarda. [Article in German]. Klin Monbl Augenheilkd 1995;206:26872. [CrossRef]

22. Lichter H, Loya N, Sagie A, Cohen N, Muzmacher L, Yassur Y, Weinberger D. Keratoconus and mitral valve prolapse. Am J Ophthalmol 2000;129:667-8. [CrossRef]

23. Bawazeer AM, Hodge WG, Lorimer B. Atopy and keratoconus: a multivariate analysis. Br J Ophthalmol 2000;84:834-6. [CrossRef]

24. McMonnies CW. Abnormal rubbing and keratectasia. Eye Contact Lens 2007;33:265-71. [CrossRef]

25. Totan Y, Hepșen IF, Cekiç O, Gündüz A, Aydin E. Incidence of keratoconus in subjects with vernal keratoconjunctivitis: a videokeratographic study. Ophthalmology 2001;108:824-7. [CrossRef]

26. Hammerstein W. Genetics of conical cornea (author's transl). [Article in German]. Albrecht Von Graefes Arch Klin Exp Ophthalmol 1974;190:293-308. [CrossRef]

27. Gonzalez V, McDonnell PJ. Computer-assisted corneal topography in parents of patients with keratoconus. Arch Ophthalmol 
1992;110:1413-4. [CrossRef]

28. Wang Y, Rabinowitz YS, Rotter JI, Yang H. Genetic epidemiological study of keratoconus: evidence for major gene determination. Am J Med Genet 2000;93:403-9. [CrossRef]

29. Klintworth GK. Advances in the molecular genetics of corneal dystrophies. Am J Ophthalmol 1999;128:747-54.

30. Holland EJ, Daya SM, Stone EM, Folberg R, Dobler AA, Cameron JD, et al. Avellino corneal dystrophy. Clinical manifestations and natural history. Ophthalmology 1992;99:1564-8. [CrossRef]

31. Fukuchi T, Yue BY, Sugar J, Lam S. Lysosomal enzyme activities in conjunctival tissues of patients with keratoconus. Arch Ophthalmol 1994;112:1368-74. [CrossRef]

32. Sawaguchi S, Yue BY, Sugar J, Gilboy JE. Lysosomal enzyme abnormalities in keratoconus. Arch Ophthalmol 1989;107:1507-10. [CrossRef]

33. Sawaguchi S, Twining SS, Yue BY, Chang SH, Zhou X, Loushin G, et al. Alpha 2-macroglobulin levels in normal human and keratoconus corneas. Invest Ophthalmol Vis Sci 1994;35:4008-14.

34. Bureau J, Fabre EJ, Hecquet C, Pouliquen Y, Lorans G. Modification of prostaglandin E2 and collagen synthesis in keratoconus fibroblasts, associated with an increase of interleukin 1 alpha receptor number. C R Acad Sci III 1993;316:425-30. [CrossRef]

35. Määttä M, Väisänen T, Väisänen MR, Pihlajaniemi T, Tervo T. Altered expression of type XIII collagen in keratoconus and scarred human cornea: Increased expression in scarred cornea is associated with myofibroblast transformation. Cornea 2006;25:448-53. [CrossRef]

36. Määttä M, Heljasvaara R, Sormunen R, Pihlajaniemi T, Autio-Harmainen $H$, Tervo T. Differential expression of collagen types XVIII/ endostatin and $\mathrm{XV}$ in normal, keratoconus, and scarred human corneas.
Cornea 2006;25:341-9. [CrossRef]

37. Wilson SE, He YG, Weng J, Li Q, McDowall AW, Vital M, et al. Epithelial injury induces keratocyte apoptosis: hypothesized role for the interleukin-1 system in the modulation of corneal tissue organization and wound healing. Exp Eye Res 1996;62:325-7. [CrossRef]

38. Bron AJ, Rabinowitz YS. Corneal dystrophies and keratoconus. Curr Opin Ophthalmol 1996;7:71-82. [CrossRef]

39. Lema I, Durán JA, Ruiz C, Díez-Feijoo E, Acera A, Merayo J. Inflammatory response to contact lenses in patients with keratoconus compared with myopic subjects. Cornea 2008;27:758-63. [CrossRef]

40. Lema I, Sobrino T, Durán JA, Brea D, Díez-Feijoo E. Subclinical keratoconus and inflammatory molecules from tears. $\mathrm{Br} \mathrm{J}$ Ophthalmol 2009;93:820-4. [CrossRef]

41. Sherwin T, Brookes NH. Morphological changes in keratoconus: pathology or pathogenesis. Clin Exp Ophthalmol 2004;32:211-7.

42. Meek KM, Tuft SJ, Huang Y, Gill PS, Hayes S, Newton RH, et al. Changes in collagen orientation and distribution in keratoconus corneas. Invest Ophthalmol Vis Sci 2005;46:1948-56. [CrossRef]

43. Klintworth GK, Damms T. Corneal dystrophies and keratoconus. Curr Opin Ophthalmol 1995;6:44-56. [CrossRef]

44. Gondhowiardjo TD, van Haeringen NJ. Corneal aldehyde dehydrogenase, glutathione reductase, and glutathione $\mathrm{S}$-transferase in pathologic corneas. Cornea 1993;12:310-4. [CrossRef]

45. Behndig A, Svensson B, Marklund SL, Karlsson K. Superoxide dismutase isoenzymes in the human eye. Invest Ophthalmol Vis Sci 1998;39:471-5.

46. Cristina Kenney M, Brown DJ. The cascade hypothesis of keratoconus. Cont Lens Anterior Eye 2003;26:139-46. [CrossRef] 